\title{
O SER E O NÃO SER DA UNIVERSIDADE PÚBLICA: O PÚBLICO E O PRIVADO EM QUESTÃO NA EDUCAÇÃO SUPERIOR BRASILEIRA.
}

\author{
Matheus Castro da Silva ${ }^{\mathrm{i}}$
}

\section{RESUMO}

Este estudo pretende investigar de que forma a Educação Superior pública se configura atualmente, levando em consideração a relação que há entre as esferas públicas e as esferas privadas em nossa sociedade. Para tanto, utilizaremos o materialismo histórico e dialético como método, em uma perspectiva para além da compreensão, mas de ação para a superação dessa realidade. Com isso, buscamos entender de que forma o Brasil está inserido na ordem mundial capitalista, que, de acordo com Ruy Mauro Marini e Florestan Fernandes, é de forma dependente e periférica e a maneira que isso se materializa em nossas relações sociais, neste caso, as políticas educacionais. Nesse sentido, discutir as relações entre o público e o privado na educação pública torna-se imperioso, porquanto vemos ataques cada vez maiores por parte do capital aos serviços públicos, utilizando-se do Estado, e da educação, como trincheiras avançadas no processo da luta de classes. Palavras-chave: Capitalismo dependente; Educação Superior; Estado.

\section{THE BEING AND THE NOT TO BEING OF THE PUBLIC UNIVERSITY: THE PUBLIC AND THE PRIVATE IN DISCUSSION ON THE BRAZILIAN HIGHER EDUCATION.}

\begin{abstract}
This study aims to investigate how the public Higher Education is currently set, taking into account the relationship between the public sphere and the private sphere in our society. To this end, we use do dialectical and historical materialism as our method, in a perspective beyond of the understanding, but seeking for action to overcome this reality. With this, we aimed to understand how is the insertion of Brazil on the capitalist world order, that, according to Ruy Mauro Marini and Florestan Fernandes, is in a way dependent and peripheral and the way that this situation materializes in our social relationships, in this case, the educational politics. In this sense, discuss the relationship between the public and the private on the public education becomes imperative, in view of we see increasing attacks by capital to the public services, using the State, and the education, how advanced trenches in the process of classes combat.
\end{abstract}

Key-words: Dependent Capitalism; Higher Education; State.

\section{Introdução.}

Este ensaio fará uma análise de uma discussão que, apesar de remontar a tempos muito anteriores, ainda é muito recorrente nos debates acerca da educação e das políticas educacionais brasileiras, sobretudo após a implementação da última Reforma Universitária. Retomar os estudos acerca da relação entre o público e o privado na Universidade nos é fundamental para a compreensão acerca da configuração atual do Ensino Superior brasileiro, além da possibilidade do entendimento sobre a relação que ocorre entre o nosso cotidiano, enquanto alunos, técnicos e professores, e a estrutura societária em que vivemos, tendo como mediação as políticas educacionais. 
Para tanto, temos como método o materialismo histórico e dialético, o método marxista, que entendemos ser aquele capaz de não apenas nos dar o melhor caminho para a compreensão da realidade e do nosso objeto, mas também nos auxiliar no processo de luta pela transformação na sociedade. Partimos da premissa que a ordem mundial está configurada em um modo de produção da existência denominado por capitalismo, e que este, ao passo que se configura em uma totalidade, se materializa de forma desigual nos mais diversos espaços, torna-se imperiosa a compreensão da particularidade brasileira.

Em um segundo momento, tentaremos entender a configuração atual do Ensino Superior brasileiro, tendo como foco a Universidade pública, fazendo a articulação entre educação e uma sociedade de capitalismo dependente, buscando ainda relacionar o conflito entre público e o privado nessa perspectiva. Nesse sentido, faremos um breve panorama do período que vai da Constituição Federal de 1988 (CF/88) até a assunção da Presidência da República por Luiz Inácio Lula da Silva, que consideramos ser uma grande inflexão na história brasileira.

Por fim, discutiremos os limites e as potencialidades da Educação Superior pública, entendendo que a educação é um campo de disputas, de tensões, de conflitos, sobretudo a educação pública. O nosso foco estará no processo de implementação da última Reforma Universitária, Decreto 6096 de 24 de abril de 2007, ou o REUNI. Buscamos entender de que forma o conflito público-privado se configurou após a elaboração desse projeto, e qual a realidade das IES públicas atualmente.

\section{A inserção dependente e a particularidade brasileira.}

Entendemos que investigar a particularidade do capitalismo no Brasil é a aplicação do método de Marx com o rigor necessário, porquanto a maneira pela qual se materializa o capitalismo no Brasil é diferente da forma pela qual ele se desenvolveu historicamente nos países considerados desenvolvidos. Para analisar o capitalismo nas sociedades dependentes, mais especificamente no caso brasileiro

é preciso colocar em seu lugar o modelo concreto do capitalismo que irrompeu e vingou na América Latina, o qual lança suas raízes na crise do antigo sistema colonial e extrai seus dinamismos organizatórios e evolutivos, simultaneamente, da incorporação econômica, tecnológica e institucional a sucessivas nações capitalistas hegemônicas e do crescimento interno de uma economia de mercado capitalista (FERNANDES, 2009, pp. 51-52).

Assim, a análise da educação superior na particularidade brasileira implica compreender mais do que as relações entre países desenvolvidos e subdesenvolvidos, alcançando as formas de manifestação da relação dialética entre imperialismo e dependência na perspectiva de reprodução global do MPC. Para tanto, é fundamental entender a metamorfose das relações e estruturas de dominação imperialistas nos processos e estruturas de subordinação, dependência.

A razão para isso é tão direta quanto complexa: com a universalização do MPC, as relações de classes também se tornam um problema mundial, particularmente para os centros de onde emanam as relações de dominação imperialistas, o que explica a importância das interferências externas em setores estratégicos da reprodução social, como é o caso da educação (MINTO, 2011, p. 100). 
É preciso marcar que, já no Manifesto do Partido Comunista, Marx e Engels visualizavam a tendência imanente de expansão do capital. A burguesia aproxima cada vez mais os povos, concentra a renda, os meios de produção nas mãos de poucos, acaba com os laços provinciais, além de desenvolver forças de produção cada vez mais maciças. As forças de produção surgidas na época feudal que, ao não suprirem mais a demanda, tornaram-se obstáculo para o seu desenvolvimento, sendo destroçadas. "No seu lugar apareceu a livre concorrência, com sua organização social e política correspondente, sob a dominação econômica e política da classe burguesa" (MARX \& ENGELS, 2008, p. 17).

É importante colocar que Marx e Engels (2008, p. 11) afirmam que o MPC só se desenvolveu dessa forma, sobretudo nos países centrais, em virtude da inserção dos países que de alguma forma se constituíram em colônias por meio da expansão do capitalismo, "a grande indústria criou o mercado mundial, preparado pela descoberta da América. O mercado mundial promoveu um desenvolvimento incomensurável do comércio, da navegação e das comunicações".

Esse processo de incorporação de forma colonial à ordem capitalista mundial teve consequências para o Brasil no que tange ao seu processo de desenvolvimento econômico, social, político e cultural, porquanto ele se constituiu em uma nação satélite do núcleo capitalista, dependendo dos impulsos advindos deste núcleo para que pudesse haver os avanços na ordem social local. Contudo, os impulsos externos passam pelas mediações da ordem sociometabólica local, que, neste caso, era uma ordem estamental, conservadora e escravista. (FERNANDES, 1968). Assim, o desenvolvimento da ordem capitalista no Brasil não ocorre por uma exploração direcionada de fora, onde as elites locais seriam vítimas, mas com essas mesmas elites sendo também beneficiárias dessa situação de dependência. "Os setores sociais que possuem o controle das sociedades latino-americanas são tão interessados e responsáveis por essa situação quanto os grupos externos, que dela tiram proveito. Dependência e subdesenvolvimento são um bom negócio para os dois lados" (FERNANDES, 2009, p. 34).

A partir da expansão comercial do século XVI, vemos o desenvolvimento da América Latina acompanhar o capitalismo internacional que se formava, baseado na produção de metais e gêneros exóticos para o centro do capital, engendrando o aumento das mercadorias em circulação e dos meios de pagamento. Com isso, houve a possibilidade de o capital comercial e bancário se desenvolver assim como houve o sustento da produção manufatureira, permitindo o crescimento da grande indústria.

No caso da industrialização europeia, o recurso à simples produção agrícola interna teria bloqueado a elevada especialização produtiva que a grande indústria tornava possível. $\mathrm{O}$ forte incremento da classe operária industrial e, em geral, da população urbana ocupada na indústria e nos serviços, que se verifica nos países industriais no século passado, não poderia ter acontecido se estes não contassem com os meios de subsistência de origem agropecuária, proporcionados de forma considerável pelos países latino-americanos. Isso foi o que permitiu aprofundar a divisão do trabalho e especializar os países industriais como produtores mundiais de manufaturas (MARINI, 1973, pp. 136-137).

Dessa forma, a implementação da educação superior no Brasil remete aos anos de 1550, quando foi criada de forma não institucionalizada pela Companhia de Jesus, com o intuito de formação de seus quadros. "Nesses primeiros tempos, a dinâmica reprodutiva da 
sociedade colonial não demandava um sistema de ensino comprometido em formar indivíduos dotados do saber e da ciência que os pudesse preparar para o exercício de qualquer tipo de autonomia intelectual" (MINTO, 2011, p. 103). E no funcionamento da estrutura jesuítica prevaleceu a lógica dos negócios coloniais, não interferindo nos interesses e negócios de Portugal, além de serem grandes beneficiários do regime escravista e exploração indígena, administrando latifúndios monocultores.

No fim do período colonial, transição do século XVIII para o século XIX, houve a criação das escolas profissionalizantes em áreas tradicionais (medicina, engenharia e direito) por conta da vinda da Coroa portuguesa para o Brasil, onde a formação de nível superior concorre para a formação da classe dominante brasileira. Era, e ainda é, uma formação pautada na conservação de classes no processo de adequação do país aos processos mais avançados do desenvolvimento do MPC. Conquanto fosse um ensino realizado no interior do país, ele possui a função de fazer a ligação entre o desenvolvimento interior da civilização e o fluxo do saber importado e acabado (MARINI, 1973)

Essa "demora" muito ocorreu por conta da política da Coroa Portuguesa que impedia a criação de Universidades aqui no Brasil para evitar a "contaminação" dos brasileiros com o ideário liberal e nacionalista que circulava na época. A esse fato articulase uma elite que poderia realizar a formação de seus filhos no exterior, majoritariamente em Portugal, onde havia um misto das ideias antiliberais burguesas e as ideias liberais que rondavam a Europa, e também relações de trabalho e um grau de desenvolvimento das forças produtivas que dispensava maiores investimentos na área da educação. Por fim, criavam-se cargos para a prestação de serviços imediatos à Coroa Portuguesa que aqui desembarcava, como preparação para os serviços burocráticos, médicos acostumados com as doenças locais, e engenheiros para dirigir um insipiente processo de urbanização (MINTO, 2011; FERNANDES, 1968).

A transferência da Corte não colocava bases nem direcionava mudanças na estruturas sociais, culturais e históricas. Essa transferência acarretava em um acirramento nas contradições da estrutura social e econômica, possibilitando maior margem para mudanças, mas que determinava a direção dos padrões e instituições transplantadas, limitando a modernização e colocando-a a serviço do aperfeiçoamento da ordem vigente, algo que não está muito distante do que vivemos atualmente. "Sob esse aspecto, a transplantação de instituições da sociedade metropolitana esbarrava em um vazio histórico, que era criado pela própria estrutura social de uma sociedade colonial escravista e senhorial" (FERNANDES, 2004, p. 281).

Seja por conta das pressões da Inglaterra, seja pela própria lógica capitalista, onde o trabalhador assalariado seria mais "barato" do que o escravo para a obtenção de lucros, observamos o início do processo de fim da escravidão no Brasil a partir da segunda metade do século XIX. No entanto, não se alteraram as bases da economia, que permaneceu agrário-exportadora, atuando para abastecer os grandes centros do capital de alimentos, no caso, bens-salários ${ }^{\mathrm{ii}}$, e também de matérias-primas, permitindo aos grandes centros concentrarem sua produção no setor manufatureiro e em seguida industrial.

Todavia, o aumento da oferta de alimentos e matéria-prima advindas das regiões periféricas como um todo, em especial do Brasil, desvaloriza a sua participação no mercado mundial, com a deterioração dos seus termos de troca se colocados em conta os 
produtos manufaturados e, posteriormente, industrializados, ou seja, que contam em sua produção com maior participação da tecnologia. Assim, os membros da classe dominante "procuram compensar a perda de renda gerada pelo comércio internacional por meio do recurso de uma maior exploração do trabalhador" (MARINI, 1973, p. 147). Aumento da intensidade do trabalho com maior exploração do trabalhador; prolongação da jornada de trabalho; e, por fim, a redução do consumo do trabalhador abaixo do que é "normal", o fundo necessário se converte em fundo de acumulação, a articulação desses três aspectos constitui o que Autor entende por superexploração do trabalho.

Essa situação é coerente com o baixo nível de desenvolvimento das forças produtivas. Se na indústria fabril, o trabalho gera ao menos gastos com matéria-prima, no extrativismo e agricultura, o aumento do trabalho no capital fixo gera menos ônus para o explorador, aumento da riqueza produtiva sem o aumento do capital investido.

A atividade produtiva baseia-se sobretudo no uso extensivo e intensivo da força de trabalho: isso permite baixar a composição-valor do capital, o que, aliado à intensificação do grau de exploração do trabalho, faz com que se elevem simultaneamente as taxas de mais-valia e de lucro (MARINI, 1973, p. 149).

Nessas condições, vemos que é negado ao trabalhador o seu acesso aos meios de subsistência e reposição de energia, remuneração abaixo do valor necessário, superexploração, com desgaste acima do necessário.

O processo de industrialização da América Latina ocorre da mesma forma, débil e subordinado aos impulsos do centro hegemônico do capital. A elevação da margem de lucro ocorre em virtude de ações como o monopólio, baixa especialização, e as barreiras alfandegárias. Ademais, mediante o baixo desenvolvimento tecnológico, o preço é determinado sobretudo pelo salário, logo, o capitalista se aproveita do exército de reserva gerado e a crise para pressionar para baixo os salários dos trabalhadores, assim, além da chance de se obter uma alta lucratividade, era a oportunidade de importar a tecnologia que já se encontrava obsoleta no centro do capital.

Essas condições, por sua vez, foram importantes para alterar a fisionomia da formação social brasileira no último quartel do século XIX, sobretudo porque permitiram a acumulação de forças sociais que passaram a pressionar por um novo tipo de adequação sócio-econômica. Nisto, a participação política das ascendentes camadas intermediárias, ainda que débil, foi fundamental (MINTO, 2011, p. 110).

Com esse início de industrialização, houve um processo de urbanização: construção de estradas, portos, ferrovias, serviços públicos de infraestrutura para e em virtude das novas atividades industriais como as indústrias alimentícias. Todavia, o processo de industrialização serviu para concentrar ainda mais o poder visto os segmentos que vieram a compor a burguesia industrial brasileira. Assim, vemos a concentração de renda e poder político no eixo Rio-São Paulo, que passam a cumprir algumas funções outrora realizadas pelos núcleos hegemônicos exteriores, o que explica o crescimento do Ensino Superior primeira nessas localidades.

A forte concentração do crescimento econômico, provocada pela industrialização, acarretou intensificação da transferência de renda e de controles econômicos de setor arcaico para o setor moderno, localizado 
no meio urbano. Nesse sentido, a região beneficiada pelo processo (o eixo econômico Rio de Janeiro-São Paulo) passou a preencher algumas das funções econômicas anteriormente saturadas por centros hegemônicos do exterior (FERNANDES, 1968, pp. 66-67).

Todavia, esse processo de início da industrialização correspondia com a necessidade de elevar o grau de instrução da população, aumentar a mão de obra qualificada, e, com isso, expandir a educação formal. Ademais, o início da industrialização também conta com o início da formação de um operariado, da importação de mão de obra estrangeira, mais acostumada com as lutas sindicais, e, assim, se dá a formação de uma classe trabalhadora que passa a exigir mais direitos e a educação se torna uma bandeira histórica.

A expansão do Ensino Superior se deu pela criação das faculdades isoladas, e "as escolas superiores agregadas entre si, mantidas e fortalecidas sua estrutura tradicional e suas tendências autárquicas pela conglomeração, passaram a ser chamadas de "universidade"” (FERNANDES, 2004, pp. 287-288). Nesse contexto, há a criação das primeiras Universidades no país, a maioria compondo o que conhecemos por "Universidade conglomerada" de acordo com Florestan Fernandes, que assim as denominava em virtude de ser uma junção de diversas faculdades isoladas sem que houvesse de fato uma articulação entre elas no processo de produção de conhecimentos, em uma tentativa de adotar o padrão europeu de Universidade, mas sem que elas tenham bases materiais para garantir o seu papel social ótimo.

O capitalismo dependente gera, ao mesmo tempo, o subdesenvolvimento econômico e o subdesenvolvimento social, cultural e político. [...] Promove a modernização limitada ou segmentada em todos os níveis da organização da economia, da sociedade e da cultura, ou seja, o subdesenvolvimento paralelo em todas as esferas da vida (FERNANDES, 2009, pp. 66-68).

Assim como a indústria brasileira dependia do processo de transplantação de tecnologia, a Universidade brasileira também se constituía em um polo de adaptação dos conhecimentos advindos do centro do capital, sem que houvesse no processo de sua criação a intenção de se constituir um lócus de um desenvolvimento autônomo, crítico. Dessa forma, há um processo de importação dos modelos educacionais vindos de fora, além das ideias, dos modelos culturais, que, ao ser aplicados aqui, sem uma base material correspondente, além de ter a mediação de uma sociedade de classes que se aproximava do padrão estamental, autoritário, já nascem em um processo que Florestan denomina de senilização precoce ${ }^{\text {iii }}$ (FERNANDES, 2004).

Nas sociedades hegemônicas, há uma certa margem de autonomia do desenvolvimento econômico, cultural e político que possibilitam a prática da dominação propriamente dita. Logo, há o benefício em prol da apropriação do excedente econômico das nações dependentes, seja aumentando a imposição de seus valores, conhecimentos e tecnologia, seja aumentando as vantagens em relação à sua posição político-estratégica. Dessa forma, há a pressão por uma neutralização da criticidade do pensamento em função da dependência e do imperialismo, onde a ideologia das nações dominantes se torna a ideologia das nações dependentes. "Não se pode esperar que a produção científica liberadora, nesse nível, seja criada nos centros de investigação e de ensino daquelas 
nações. Se quisermos dispor desse tipo de conhecimento, termos de produzi-lo por nossos próprios meios" (FERNANDES, 2009, p. 129).

Outro fator relevante para esse processo são alguns grupos de intelectuais, que preferem manter um determinado status, certos privilégios, além do medo da repressão e acabam também se subordinando a essa lógica do transplante de conhecimentos. Assim, vemos que as Universidades "[...] aceitam modelos inócuos ou contraproducentes, porque seus educadores, cientistas e tecnologistas preferem preservar o nível de prestígio vinculado à associação com os centros mais avançados" (FERNANDES, 2009, p. 136). Ademais, também vemos as influências organizadas com o propósito de direcionar a mudança de acordo com os interesses da dominação externa e da contrapartida para os setores dominantes internos, como acontece em muitos programas educacionais que possuem fins de desenvolvimento científico-tecnológico, numa clara tentativa de dissimulação da intensificação da dependência. Outrossim, como as ideologias das nações desenvolvidas são absorvidas pelas demais, por meio da hegemonia burguesa e funções estatais, os próprios intelectuais acabam adquirindo certas debilidades, transformando-se nos próprios porta-vozes dessa ideologia

No entanto, seja por conta do engajamento de alguns intelectuais, seja por conta da ampliação da participação da classe trabalhadora na Universidade, ainda que limitada a alguns segmentos da classe trabalhadora, esta se constituiu em um amplo espaço de embates teóricos e políticos da luta de classes. É a tentativa de a burguesia brasileira, ainda que com pequenas concessões, manter o seu domínio, mesmo que para isso sacrifique qualquer perspectiva de progresso ou desenvolvimento local. Com isso, vemos que o ensino superior brasileiro

se prendia a uma composição de resíduos educacionais ou institucionais arcaicos com interesses estamentais ou de classes, que só poderia ter algum sentido dinâmico no contexto histórico da formação do capitalismo dependente no Brasil. Não só estava montado para servir às relações de dependência; dava suporte a uma orientação tipicamente conservadora, que esvaziava a contribuição das escolas superiores para a transplantação cultural de significado histórico mais ou menos perturbado. Em consequência, operava como uma sorte de agente mecânico de transferência cultural, restringindo as inovações ao âmbito do pensamento abstrato, da falsa erudição e das racionalizações compensatórias, que movimentavam verbalmente os símbolos do "progresso cultural" (FERNANDES, 2004, p. 297).

Dessa feita, vemos a relação dialética estabelecida entre o processo de desenvolvimento do ensino superior e a inserção brasileira na ordem mundial do capital. $\mathrm{O}$ Ensino Superior pautado no processo de transplante de conhecimentos corroborava com uma inserção periférica no MPC, enquanto a base das relações sociais de produção também determinavam à Universidade um papel dependente no âmbito da produção do conhecimento.

\section{Da Constituição Federal de 1988 ao Governo PT: Os caminhos percorridos pela Universidade na particularidade brasileira.}

Fazer a análise da educação superior na particularidade brasileira implica compreender mais do que as relações entre países desenvolvidos e subdesenvolvidos, 
alcançando as formas de manifestação da relação dialética entre imperialismo e dependência na perspectiva de reprodução global do MPC. Para tanto, é fundamental entender a metamorfose das relações e estruturas de dominação imperialistas nos processos e estruturas de subordinação, dependência. Sendo assim, a educação é uma totalidade complexa, sendo um processo histórico resultado de uma amálgama de determinações.

A razão para isso é tão direta quanto complexa: com a universalização do MPC, as relações de classes também se tornam um problema mundial, particularmente para os centros de onde emanam as relações de dominação imperialistas, o que explica a importância das interferências externas em setores estratégicos da reprodução social, como é o caso da educação (MINTO, 2011, p. 100).

Nesse sentido, iniciaremos esta seção de um grande marco na história recente brasileira, a elaboração da Constituição Federal de 1988. Um período contraditório se formos pegar a conjuntura mundial. Se no resto do mundo, sobretudo nos países desenvolvidos, havia a ascensão do neoliberalismo, com o processo de reestruturação do capital $^{\text {iv }}$, no Brasil o sentido era inverso. Com a derrocada do regime militar, vemos o processo de abertura política ser marcado pelo fortalecimento dos movimentos sociais, o que foi reforçado pelo processo de anistia, com o retorno de líderes e intelectuais exilados durante esse período.

Nesse contexto, de uma maior abertura política, temos como consequência a elaboração da CF/1988. Fundada em uma base de direitos sociais e coletivos, em que a efetivação destes não foi garantida. A Constituinte dessa época teve a participação da sociedade civil organizada por meio de entidades coletivas representativas de diversos interesses. "Novos temas, velhas posturas; o novo revestido do arcaico; o consagrado enrolado em roupagens atualizadas, tudo isto aparece na confecção dos diferentes capítulos, inclusive no da educação" (CURY; HORTA; FÁVERO, 2005, pp. 22-23).

Sendo assim, a Constituição ganha um caráter formal mais progressista, se levarmos em conta a participação efetiva dos diversos movimentos sociais, e de uma esquerda mais organizada. Com relação à educação, o maior conflito foi relacionado à destinação de recursos públicos: a grande dualidade público/privado. O público agora desmembrava-se em estatal, não-estatal e serviço, onde a diferença estava na questão da lucratividade ou se haveria uma posição de exclusividade do Estado na prestação de certos serviços. Haveria o reconhecimento de escolas oficiais particulares com fins lucrativos. Assim, vemos a dualidade entre o conservador e o progressismo.

Assim, vemos que a burguesia necessitava de alguém para preencher o vácuo que ficou desde o fim da Ditadura. Em virtude da falta de unidade das forças conservadoras, a candidatura à presidência de Lula da Silva ganhava força, sendo derrotada apenas em virtude da coalização de todas as forças de direita em torno do nome de Collor. Dessa forma, o período de 1989 dava início a um grande processo de contrarreforma após a $\mathrm{CF} / 88$.

Os projetos do Governo Sarney foram efetivados como políticas de Estado por Collor, o fechamento das autarquias, fundações e empresas públicas, inclusive Coordenação de Aperfeiçoamento de Pessoal de Nível Superior (CAPES) e Instituto Nacional de Estudos e Pesquisas Educacionais (INEP), reabertos após a pressão do meio acadêmico. Assim, vemos a elaboração do primeiro Plano Setorial de Educação (91-95), 
que condicionava a autonomia das universidades à uma comprovação de seu desempenho, gerando uma grande reação ao projeto de avaliação institucional.

O ministro da Educação Carlos Chiarelli concordava plenamente com o diagnóstico da missão do Banco Mundial, de que as universidades federais tinham excesso de pessoal, priorizavam as atividades-meio em detrimento das atividades-fim, impondo-se, portanto, a adoção de procedimento drásticos de redução do custo unitário do estudante (CUNHA, 1997, pp. 26-27).

Dessa forma, o ministro colocou dois caminhos para o cumprimento das metas acima elencadas: redução de $1 / 3$ com os gastos de pessoal das Universidades, ou expansão em $30 \%$ do corpo discente, em especial cursos noturnos e de cidades do interior.

Todavia, após falhar em seu plano de estabilização econômica, ver a inflação aumentar enormemente, Collor teve sua base política altamente comprometida. Aliado a isso, vemos as denúncias de corrupção, e do envolvimento de sua família, gerando grandes movimentos a nível nacional para a sua saída, que se concretizou em 1992. Com relativo sucesso em relação à contenção da inflação, mesmo que arcando com enormes custos sociais, Fernando Henrique Cardoso (FHC), por meio do Plano Real, adquiriu bastante popularidade, sendo eleito presidente em 1994.

Esse foi um governo totalmente afinizado com os ditames do Banco Mundial (BM), inclusive corroborando com a lógica deste organismo ao afirmar que a crise dos anos 70,80 foi uma crise de Estado e não do capitalismo. Nesse sentido, o Ministro Bresser-Pereira afirmava a necessidade de uma reconfiguração no Estado, não o Estado mínimo neoliberal, mas uma contração que permitisse a eficiência no Governo. "Houve a dilapidação do patrimônio público, a desvalorização dos servidores com achatamento salarial e perda de direitos, o abandono de áreas como a saúde e a educação e a ênfase em áreas gerenciais como fiscalização, diplomacia e agências reguladoras" (GREGÓRIO, 2011, p. 74). Ademais, há o novo conceito de "publicização", onde as empresas privadas atenderiam aos interesses públicos, com grande aporte financeiro estatal.

Era uma perspectiva que condenava os "grandes" gastos com a rede federal, que abrangiam uma menor quantidade dos estudantes de Ensino Superior, comparada à rede privada, uma proposta de redistribuição de recursos para as instituições de maior produtividade, independente de sua origem. A proposta de reforma envolvia uma racionalização dos gastos, com utilização dos espaços ociosos, aumentando os cursos noturnos, e o número de matrículas sem que houvesse aumento de custos. Por fim, a autonomia das universidades entraria nessa perspectiva de disputa pelas verbas públicas com a sua produtividade. Não se planejava aumentar os gastos com o Ensino Superior público, que deveria ter seus custos aumentados a partir de cooperações com outros segmentos sociais (CUNHA, 1997).

Dessa feita, de acordo com Gregório (2011), o movimento contrarreformista de FHC agiu de forma dual: a expansão das instituições da iniciativa privada, e a privatização "por dentro". Dessa forma, vemos que o modelo de universidade humboldtiana, ensino, pesquisa e extensão, passa a ser questionada e combatida. Já em Collor vemos a defesa do modelo da "Universidade de Ensino", a diversificação do Ensino Superior. Todavia, é apenas no Governo FHC que isso se torna uma diretriz do Ministério da Educação (MEC), de acordo com as prerrogativas do BM. Ademais, na Lei de Diretrizes e Bases de 1996 
(LDB/96) vemos o marco regulatório que coloca as Universidades públicas no patamar das Organizações Sociais, quebrando o Regime Jurídico Único (RJU) nas Instituições Federais de Ensino Superior (IFES), além de abrir as portas para a iniciativa privada financiar a educação pública. Articulando-se isso à proibição da abertura de concursos públicos, inicia-se um processo extensivo de contratação de professores, em condições totalmente precárias. Isso atendia a diversas demandas do BM, a quebra do RJU, a não entrada desses professores na previdência, a não possibilidade de desenvolvimento de outras atividades que não sejam o ensino.

Por fim, em 2001, há a aprovação do Plano Nacional de Educação (PNE), que continha as metas a serem alcançadas nos próximos 10 anos, concretizando a transferência de responsabilidades do Governo para a sociedade, no que concerne ao financiamento da educação, e o embasamento na teoria do Capital Humano, a educação como redução das desigualdades sociais. Era a afirmação da necessidade de diversificação do ES, o estímulo às instituições não-universitárias, sistemas de avaliação produtivistas, grande sistema de oferecimento da EAD, flexibilização curricular e afins (GREGÓRIO, 2011).

\section{O Governo do Partido dos Trabalhadores: grandes mudanças para manter o mesmo caminho.}

Em 2002, com a vitória nas eleições presidenciais de Lula, que concorreu pelo Partido dos Trabalhadores, vemos as grandes expectativas da classe trabalhadora e dos diversos movimentos sociais. Ainda que pudesse não ocorrer um grande giro à esquerda em seu governo, esperavam-se medidas progressistas de sua parte. Todavia, já na assinatura da "Carta ao povo brasileiro", Lula mostrou de que lado estava. E desse jeito tocou seu governo, intensificando as proposições neoliberais de seu antecessor. Houve sim mudanças com o aumento do investimento nas políticas sociais, atuando para amenizar os efeitos do neoliberalismo por meio de políticas focais de "alívio da pobreza", de acordo com o BM. Todavia, a implementação do neoliberalismo necessitava da adesão da classe dos subalternos, e o PT é a possibilidade de alcançar esse intento, por meio do "Pacto Social". (GREGÓRIO, 2011).

O cerne da contrarreforma do Estado foi a consolidação do "Público não estatal", ou seja a formação das Parcerias Público-Privadas e o funcionamento por contratos de gestão, que materializaram a política "entreguista" de áreas como a Ciência \& Tecnologia, infraestrutura, energia, e serviços sociais, como educação e saúde. Nesse sentido, o carrochefe das políticas do Partido dos Trabalhadores foi o PAC, Programa de Aceleração do Crescimento, que continha como conteúdo fundamental um marco regulatório de abertura desses espaços para a iniciativa privada; preconizava o superávit primário como meio de pagamento das dívidas externas e de seus serviços; e o corte nos custos com os serviços sociais, como saúde e educação (BOITO JÚNIOR, 2005).

Nesse sentido, vemos a educação ser colocada como um "bem público". O que isso significa? Que enquanto um bem público, ela poderia ser oferecida tanto pela iniciativa pública estatal, quanto pela iniciativa privada, sendo um serviço essencial à sociedade, e que o Estado deveria apoiar. Com isso, vemos uma série de medidas que corroboram com a lógica privatista como o PROUNI e o FIES ${ }^{v}$.

A educação possui uma ampliação do seu potencial econômico, constituindo-se como "organizações terciárias": podem ser prestadoras do serviço "ensino"; e também 
podem ser prestadores de serviço, no caso daquelas com cursos de Pós-Graduação estruturados, área de pesquisa desenvolvida, para empresas que não disponham de setores de pesquisa e desenvolvimento próprios. Todavia, mesmo quando se busca uma formação para o mercado, para a competitividade, não se refere a uma formação autônoma, com base nos conhecimentos mais avançados.

Na particularidade brasileira, ela adquire o significado de uma formação também adaptativa, para produção de "competências" adaptativas. Do ponto de vista dos setores econômicos que demandam essa força de trabalho, trata-se de baratear seus custos de produção e reprodução (MINTO, 2011, p. 234).

No setor econômico, isso significa o aumento da taxa de lucratividade, o aumento do apelo pela educação; na área pedagógica, significa a difusão da ideologia vazia de conteúdos, do "aprender a aprender", maneira pela qual a classe dominante passa a responsabilidade da educação, da "adaptabilidade" ao conjunto de trabalhadores.

Destarte, corroboramos com Valdemar Sguissardi (2008, p. 1014), quando ele nos coloca que, a ação sobre a educação superior pública é interessante para todas as frações burguesas que atuam no Brasil: se por um lado, a certificação em larga escala cria um exército de reserva mais qualificado, pressionando para baixo os salários dos trabalhadores; todavia, se de outro lado, esse exército tem baixa qualificação, a médio e longo prazo, o processo produtivo estará comprometido.

Neste sentido, e porque são distintos os interesses imediatos de ambos os tipos de empresários, os industriais, comerciais ou outros, em geral, tendem a valorizar mais a educação superior estatal pública, pela muito maior possibilidade, revelada pela história e pelas "avaliações", de produzir os profissionais que lhes interessam como instrumentos de valorização de seus produtos, de seu capital.

Assim sendo, veremos quantitativamente como se deu o processo de expansão que o Ensino Superior passou do Governo FHC até o Governo Lula em 2006. Se o número de Instituições privadas com fins lucrativos era de $48 \%$ do total das Instituições de Ensino Superior em 1994, em 2006, elas passam a compor $70 \%$ deste total. No que tange ao número de matrículas, as IES com fins lucrativos obtiveram um crescimento de $195 \%$ nesse período, enquanto as privadas sem fins lucrativos cresceram $45 \%$, e as públicas 97,3\%. (SGUISSARDI, 2008).

Nesse ínterim das políticas públicas para a educação superior, o REUNI, Decreto 6096/2007, que sistematizava basicamente todas as políticas para o Ensino Superior nacional, tendo como uma das metas, a redução da evasão no Ensino Superior e a expansão das vagas, sobretudo noturnas (VARGAS \& PAULA, 2013). Tendo como bandeiras a democratização, expansão e interiorização do Ensino Superior, essa Reforma Universitária se utiliza da cooptação de formulações históricas da classe trabalhadora, para a implementação e aprofundamento do projeto neoliberal para a educação.

Era o processo que preconizava a reestruturação das IFES permitindo uma ampliação do acesso e permanência no ES. Tendo como principais objetivos a obtenção da taxa de conclusão de curso para $90 \%$ e o aumento da relação entre professor e aluno para 18, o REUNI busca a expansão do ES. Para tanto, sem que haja um aumento proporcional nas verbas destinadas ao ES, recomenda-se a otimização do uso da infraestrutura existente, 
mas que já era insuficiente para a demanda antiga, causada justamente pela falta de investimentos. O Projeto também coloca a importância da redução da evasão, ocupação de vagas ociosas, e aumento das vagas de graduação, sobretudo nos cursos noturnos. No entanto, o MEC ressalta que não se deve adotar um único modelo, mas respeitando a autonomia universitária e as particularidades das IFES, cada uma poderia escolher como fazer, desde que cumprissem as metas nos 5 anos propostos. Ademais, vemos, de acordo com as prerrogativas do BM, a hierarquização entre as IFES, onde se criariam as Universidades de Excelência, nos centros regionais, e a interiorização seria feita com base em cursos de graduação formando a Universidade de Ensino, sem qualquer articulação com atividades de pesquisa e extensão. (GREGÓRIO, 2011; LIMA, 2006).

A isso, vemos a total precarização das condições do trabalho docente, com o a expansão desmesurada da quantidade de alunos, comprometendo seriamente o processo de ensino e aprendizagem, a falta de apoio técnico e financeiro para a realização de pesquisas e extensão, a reposição insuficiente do quadro docente, intensificando ainda mais o trabalho daqueles presentes, o acúmulo de funções do docente. Assim, apesar de toda a propaganda sobre o aumento de verbas "é importante salientar que o incremento de $20 \%$ no orçamento de custeio previsto no REUNI para uma ampliação no número de estudantes da ordem de $100 \%$, significa na prática numa redução real da relação de custeio por estudante" (GREGÓRIO, 2011, p. 115). Ademais, esse financiamento, ainda que insuficiente, é realizado sobre a perspectiva gerencial, dos contratos de gestão, onde os recursos serão liberados de acordo com o número de matrículas feitas. Por fim, vemos que as Universidades que não aderissem teriam suas verbas realocadas para outras instituições o que aumentou ainda mais a pressão para a assinatura.

Por fim, colocamos as consequências diretas do adensamento privatista no processo de produção de conhecimento, que é cada vez menos revertido para o restante da sociedade, que custeia a Universidade, e voltado para a lógica do mercado, pertencendo aos grandes grupos que financiam os laboratórios $\mathrm{e}$ as atividades de pesquisa, descaracterizando totalmente o papel da Universidade pública.

No que diz respeito às pesquisas, essas diretrizes sinalizam que a investigação deve servir, de um lado, para a captação de recursos adicionais, fazendo frente à dramática penúria financeira e, de outro, para suprir as necessidades de pesquisa e desenvolvimento (P\&D) que, conforme a experiência capitalista internacional comprova, deveriam ser desenvolvidas nas empresas (LEHER, 2005, p. 239).

Após estabelecermos do panorama da implementação do REUNI nas Universidades brasileiras, apontando algumas de suas consequências, avançaremos no nosso objeto específico de estudo, que é a tentativa de compreensão da relação público-privada no Ensino Superior nacional.

Nesse sentido, trazemos alguns marcos importantes para a compreensão da configuração atual dessa relação. Caracterização da educação como "bem público", com aparato político-jurídico para a diluição entre o público e o privado; compromisso social da universidade voltado para a transferência do conhecimento e tecnologia, mantendo a tendência de adaptação do conhecimento externo; aprofundamento da diversificação das IES e dos cursos, com o aligeiramento da formação, dissociação do tripé ensino, pesquisa e extensão, e a certificação em larga escala; estabelecimento de parcerias com estabelecimentos estrangeiros sob a prerrogativa de inserção internacional e intercâmbio, 
com a possibilidade de reconhecimento pelas instituições privadas brasileiras dos diplomas de mestrado e doutorado expedidos externamente;

O empresariamento da educação superior que foi iniciado com o governo Collor-Itamar, ganhando nova racionalidade com o governo Cardoso, será aprofundado no governo Lula da Silva a partir de um duplo mecanismo: a ampliação do número de cursos privados e a privatização interna das instituições públicas (LIMA, 2006, p. 38).

Com isso, vemos que, contrariando as expectativas da classe trabalhadora, o governo do Partido dos Trabalhadores atua no sentido de ampliar a participação privada na educação, agindo em conformidade com os ditames das diretrizes dos organismos supranacionais como Banco Mundial, Fundo Monetário Internacional e Organização Mundial do Comércio, demonstrando o processo de heteronomia cultural, política, econômica e social, reafirmando os conceitos de Florestan Fernandes. A desestruturação do ensino superior nacional, a exaltação ao privatismo, o desencorajamento à realização de pesquisas, com a maior hierarquização entre as Universidades de excelência, uma minoria que produz pesquisas, e as Universidades de ensino, que não possuem essa centralidade, acabam corroborando com a perspectiva de educação dentro de um país de capitalismo dependente e subordinado.

\section{O Ensino Superior hoje: limites e possibilidades na luta pela educação pública, gratuita e de qualidade socialmente referendada.}

Em um momento bastante complexo na conjuntura brasileira, sobretudo em virtude da grande onda de manifestações em Junho e Julho de 2013, que ganha continuidade atualmente com a greve de diversos segmentos da educação do Rio de Janeiro, a discussão do Ensino Superior se torna muito relevante. O questionamento ao projeto de sociedade, e às políticas implementadas em todos os âmbitos de poder, municipal, estadual e federal, deixam bem clara a necessidade de mudanças e do estabelecimento de reformas, que tenham pelo menos um cunho mais progressista de ampliação dos direitos básicos e da qualidade dos serviços sociais que são ofertados.

Resgatando um pouco um passado não tão distante, observamos a histórica greve de 2012, que atingiu 95\% das Instituições Federais de Ensino Superior, alcançando os três segmentos dessas instituições: o corpo docente, que puxou a greve, o corpo discente e o corpo de servidores, sendo em seguida acompanhada por grande parcela do funcionalismo público federal, quase 150 mil servidores em greve. É importante colocar que essa greve ocorreu no ano de 2012, o ano final da implementação do REUNI nas IFES, ou seja, foi uma clara resposta aos ataques realizados às condições de trabalho e estudo na Educação Superior pelo Governo brasileiro.

Por que fazer essa retomada? Acompanhamos um processo de ebulição das discussões acerca da educação e das políticas educacionais. A realização das CONAEs (Conferências Nacionais de Educação), ainda que em sua fase embrionária, o processo final de elaboração e discussão do novo Plano Nacional de Educação, e, sobretudo, os processos de discussão para a implementação de uma nova Reforma Universitária, o REUNI 2, tendo como base o "sucesso" da Reforma anterior.

Como um material empírico, utilizaremos as "Notas técnicas para o PNE 20112020: metas e estratégias", como aquilo que o Governo pretende para pautar suas políticas 
e estabelecer na educação nacional nos próximos 10 anos. Vemos, então, a $12^{\mathrm{a}}$ Meta, que se propõe a elevar a taxa bruta da população no Ensino Superior para 50\%, e a taxa líquida dos jovens entre 18 e 24 anos para 33\%. Como já se foi falado, a expansão e consequente democratização do Ensino Superior não é um problema. Contudo, o que nos causa preocupação é a forma e as justificativas com as quais se pretende fazer isso. Utilizando os paradigmas desenvolvimentistas das décadas de 50 e 60, defende-se "no âmbito macro, também é inquestionável a relevância da educação, e principalmente da educação superior, para a caminhada rumo ao desenvolvimento e a geração de inovações tecnológicas e dinamismo econômico" (BRASIL, 2011, p. 77). Todavia, o que mais nos preocupa se encontra ao final dessa nota. Supondo que a maior expansão da oferta de vagas no ES para o
cumprimento das metas ocorreria nas IES privadas e levando-se em conta
que o maior potencial de novos estudantes de ES encontra-se entre os
indivíduos de renda mais baixa e, portanto, pertencem a famílias com
menor capacidade de financiamento, haverá necessidade de expandir
programas de concessão de bolsas e financiamento, como ProUni e FIES.
(BRASIL, 2011, p. 80).

Nesse sentido, o que presenciamos é a clara permanência das políticas privatistas, compostas tanto pela "desresponsabilização" do Governo quanto às suas tarefas, neste caso, a oferta de educação pública, gratuita e de qualidade, quanto pela transferência de recursos públicos para o fortalecimento do setor privado, fortalecimento o processo de empresariamento e mercantilização da educação.

Com isso, vemos um aumento assustador na expansão de matrículas no ensino superior privado com fins lucrativos, o que pode ser justificado por: crise das instituições confessionais, criação do fomentos aos setores privados por meio do PROUNI, possibilidade de as IES privadas concorrerem por verbas públicas em virtude das leis de C\&T. Mesmo quando há o financiamento total pelo PROUNI, não há gratuidade, já que são recursos públicos utilizados para financiar o setor privado, de acordo com a lógica do capital. Isso ocorre também no caso da isenção fiscal, onde os lucros são obtidos por meio de apropriações do aporte público. Ademais, é fundamental ressaltar que o poder público concedia mais benefícios às instituições com fins lucrativos do que àquelas sem fins lucrativos, estimulando uma conversão (MINTO, 2011).

Dessa feita, coadunamos com Autor (MINTO, p. 247), quando este nos coloca que

Como o interesse é "público", a relação entre Estado e setor privado não pode, nessa metamorfose ideológico-conceitual, se transformar num problema. Ao contrário, pode ser vista como uma relação entre concorrentes, seja na divisão entre IES públicas e IES privadas (com ou sem fins lucrativos), seja também no interior das IES públicas como uma forma de autorizar a ingerência de recursos privados para atividades institucionais (ensino, pesquisa e extensão) e o seu oposto, a destinação de recursos públicos para atividades de interesse privado. Neste sentido, o "bem público" está para a concepção de educação assim como o "público não estatal" está para o Estado e o conjunto das IES que formam a rede de educação superior no país.

Com isso, coloca-se a necessidade da luta pela retomada dos princípios da educação pública, gratuita e de qualidade, e que isso se torne política pública. Um dos passos 
fundamental seria o fim dessa ambiguidade que paira sobre o conceito de bem ou serviço público, porquanto entendemos que o público pode ser apenas ofertado pelo Estado, não de acordo com os fins particulares. Dessa forma, a nossa luta é de caminhar na contramão das políticas atuais, neste caso as educacionais, onde a distância, os marcos separatórios entre a esfera pública e a esfera privada se encontram cada vez mais diluídos, e os serviços sociais, como educação, saúde e segurança, se encontram cada vez mais perante a lógica do lucro e do mercado.

Sendo assim, colocaremos o projeto de educação que acreditamos, em especial o modelo de Universidade que defendemos. Entendemos que a questão não pode ser apenas quantitativa, mas sim de um projeto social, econômico, acadêmico, científico, político que se estabelece para o Ensino Superior e a sua oferta no país, implicando também no próprio projeto societário que o país tem, abordando também a questão da qualidade da oferta dessa modalidade de ensino. "Nesse sentido, a universidade deve ser o lugar onde se desenvolva um processo teórico-crítico de ideias, de opiniões, de posicionamentos e também um espaço capaz de gestar propostas concretas, visando ao desenvolvimento efetivo da sociedade" (FÁVERO \& SGUISSARDI, 2012, p. 63).

\section{Conclusão.}

Em última análise, partiremos da fala da professora Autor e do professor Autor, que colocam o papel de protagonismo que a Universidade deve ter para com o restante da sociedade, a sua responsabilidade no processo de produção e disseminação de cultura e conhecimento, e, sendo assim, um dever de atuar na luta por uma sociedade mais justa e igualitária.

Destarte, podemos entender os processos constantes de ataque que o Ensino Superior vem sofrendo para evitar ao máximo que se cumpra o seu papel de formação crítica, e atue de forma contrária, no sentido da manutenção e perpetuação do status quo. É dessa forma que enxergamos as últimas políticas educacionais, que, ao se apropriarem de bandeiras históricas da classe trabalhadora, atuaram no sentido de desestruturar o Ensino Superior público brasileiro, abrindo espaço para a inserção da iniciativa privada sob a lógica do capital.

Tendo em vista os próprios documentos emitidos pelo Governo Federal, onde se coloca a necessidade de investimento no setor privado da educação, soa para nós como mais um grande ataque à educação pública, porquanto os investimentos que já são insuficientes no setor público de ensino, se tornarão ainda mais escassos, em prol do fortalecimento da atuação do capital em um setor como a educação, mas que vem acontecendo em outros serviços essenciais para a educação, como a proposta da EBSERH, das OS, frutos de um mesmo marco regulatório implementado pelo Governo Lula, o PAC.

A política de obtenção de superávit primário, ou seja, a obtenção de rendas para o pagamento da dívida externas e de seus juros às custas de vultuosos cortes nos serviços sociais, faz com que coloque-se em voga um processo de sucateamento dos serviços públicos, abrindo-os para o usufruto do capital, o que é altamente conciliatório com um período de crise do capital, onde este deve se expandir para as mais diversas áreas, e transformar "tudo em mercadoria" como já dizia Karl Marx.

Dessa feita, discutir a relação entre o público e o privado é fundamental para entender, não apenas os rumos que o Estado brasileiro está tomando, mas também para 
tirar desse entendimento as formas mais adequadas de se combater e corrigir esses rumos. Em um momento onde o descontentamento com a estrutura societária e, sendo assim, as políticas de Estado, se encontra insuflado, é importante abrir um espaço de reflexão para que as lutas não se percam e se obtenham vitórias concretas, indo assim na contramão do desenho socioeconômico atual, em prol da classe trabalhadora e não do capital.

\section{Referências.}

BOITO JUNIOR, Armando. A burguesia no Governo Lula. Crítica Marxista (São Paulo), Rio de Janeiro, v. 21, p. 52-77, 2005.

BRASIL. Ministério da Educação. O PNE 2011-2020: Metas e estratégias. Disponível em: http://fne.mec.gov.br/images/pdf/notas_tecnicas_pne_2011_2020.pdf. Acesso em: 15/07/2013.

CUNHA, Luiz Antonio. Nova reforma do Ensino Superior: a lógica reconstruída. Cadernos de Pesquisa. n.101. p.20-49. 1997.

CURY, Carlos Roberto Jamil; HORTA, José Silvério Baía; FÁVERO, Osmar. A relação educação-sociedade-estado pela mediação jurídico-constitucional. Pg. 5-30. IN: FÁVERO, O (org). A educação brasileira nas constituintes: 1823-1988. 3.ed. Campinas: Autores Associados, 2005.

FÁVERO, Maria de Lourdes de Albuquerque; SGUISSARDI, Valdemar. Quantidade / Qualidade e educação superior. Revista Educação em Questão, Natal, v. 42, n. 28, p. 6188, jan./abr. 2012.

FERNANDES, Florestan. Sociedade de classes e subdesenvolvimento. Rio de Janeiro: Zahar Editores, 1968.

Universidade e desenvolvimento. Pg. 272-316. In: IANNI, O. (org.). Florestan Fernandes: sociologia crítica e militante. São Paulo: Expressão Popular, 2004.

São Paulo: Global, 2009.

Capitalismo dependente e classes sociais na América Latina. 4.ed.

GREGÓRIO, José Renato Baez de. Política de pessoal docente no Governo Lula: Uma análise do REUNI na UFF e seus desdobramentos. 2011. 259f. Dissertação (Mestrado em Educação). Faculdade de Educação. UFF, Niterói. 2011.

HARVEY, David. O novo imperialismo. Trad: SOBRAL, A.; GONÇALVES, M.S. 2.ed. São Paulo: Edições Loyola, 2005.

LEHER, Roberto. Florestan Fernandes e a universidade no capitalismo dependente. Pg. 211-245. IN: FÁVERO, O. (org). Democracia e Educação em Florestan Fernandes. Campinas, Autores Associados; Niterói, Editora da UFF, 2005.

LIMA, Katia Regina de Souza. Capitalismo dependente e "Reforma universitária consentida": a contribuição de Florestan Fernandes para a superação dos dilemas educacionais brasileiros. In: SIQUEIRA, A.C. de; NEVES, L.M.W. (orgs). Educação superior: uma reforma em processo. São Paulo: Editora Xamã, 2006. 
MARINI, Ruy Mauro. Dialética da dependência, 1973 In: STEDILE, J.P.; TRASPADINI, R. (orgs.). Ruy Mauro Marini vida e obra. São Paulo: Expressão Popular, 2011.

MARX, Karl. Grundrisse - Manuscritos econômicos de 1857 e 1858: Esboços da crítica da economia política. São Paulo: Boitempo; Rio de Janeiro: Editora UFRJ, 2011.

MARX, Karl; ENGELS, Friedrich. Manifesto do partido comunista. São Paulo: Expressão Popular, 2008.

MINTO, Lalo Watanabe. A educação da "miséria": particularidade capitalista e educação superior no Brasil. 2011. 326f. Tese (Doutorado em Educação). Faculdade de Educação. Unicamp, Campinas. 2011.

SGUISSARDI, Valdemar. Modelo de expansão da educação superior no Brasil: predomínio privado/mercantil e desafios para a regulação e a formação universitária. Educação e Sociedade, Campinas, vol. 29, n. 105, p. 991-1022, set./dez. 2008.

VARGAS, Hustana Maria; PAULA, Maria de Fátima Costa de; A inclusão do estudantetrabalhador e do trabalhador-estudante na Educação Superior: desafio a ser enfrentado. Avaliação, Campinas; Sorocaba, SP, v. 18, n. 2, p.459-485, jul. 2013.

\footnotetext{
${ }^{\text {i }}$ Mestrando do Programa de Pós-Graduação em Educação da Universidade Federal Fluminense - Bolsista CAPES.

ii Bens-salários: são os produtos consumidos pelo trabalhador para a reposição de sua força de trabalho. Ler mais em Marx, 2011.

iii Florestan Fernandes denomina esse processo de incorporação de estruturas, instituições e valores vindos de fora de senilização precoce em virtude de esses constituírem um processo de modernização de acordo com a realidade brasileira, mas que, por não ter uma base material apropriada para a sua implementação, além de um regime autoritário, recém-saído do escravismo, com relações de trabalho que ainda não eram capitalista, acabavam se tornando obsoletos, ou senis, sem cumprir com as funções que aqui poderiam adquirir.

${ }^{\text {iv }}$ Conferir Harvey (2005); Minto (2011); Gregório (2011).

${ }^{v}$ Sinaes - Lei 10861/2004; Parceira entre as Universidades e as Fundações de direito privado, captação de financiamento privado para as IFES, Decreto 5205/2004; Lei de Inovação Tecnológica 10973/2004, parceiras entre as instituições públicas de pesquisa e o setor produtivo, privado ou não; Projeto de Parceria Público Privada Lei 11079/2004; Programa Universidade para Todos (PROUNI), Lei 11096/2005, incentivos fiscais; Universidade Aberta do Brasil, EAD; REUNI; Banco de Professor-Equivalente. (GREGÓRIO, 2011).
}

Recebido: fevereiro-14 Aprovado: novembro-14 